\title{
Novel Application of Chemical Cold Packs for Treatment of Exercise-Induced Hyperthermia: A Randomized Controlled Trial
}

John B. Lissoway, MD; Grant S. Lipman, MD; Dennis A. Grahn, PhD; Vinh H. Cao; Michael Shaheen, MD; Samson Phan, PhD; Eric A. Weiss, MD; H. Craig Heller, PhD

From the Division of Emergency Medicine, Stanford University School of Medicine, Stanford, CA (Drs Lissoway, Lipman, and Weiss); the Department of Biology, Stanford University, Stanford, CA (Drs Grahn and Heller; Mr Cao); the Department of Engineering, Stanford University, Stanford, CA (Dr Phan); and the Stanford-Kaiser Emergency Medicine Residency, Stanford, CA (Dr Shaheen).

Objective.-Heat-related illness is a common disease with significant morbidity and mortality. Despite no proven efficacy, application of chemical cold packs (CCP) to the skin overlying the large vessels of the neck, groin, and axillae is a traditional recommended cooling modality. The study objective was to compare the cooling rates of $\mathrm{CCP}$ applied to these traditional areas vs the glabrous skin surfaces of the cheeks, palms, and soles in exercise-induced hyperthermia.

Methods. - Ten healthy adult male volunteers walked on a treadmill in a heated room $\left(40^{\circ} \pm 0.5^{\circ} \mathrm{C}\right)$ while wearing insulated military overgarments until their esophageal temperatures $\left(\mathrm{T}_{\mathrm{es}}\right)$ reached $39.2^{\circ} \mathrm{C}$. Each participant had three heat stress trials on separate days: no treatment followed by randomly ordered traditional (neck, groin, and axillae) cooling and glabrous skin cooling.

Results. -With no treatment, $\mathrm{T}_{\mathrm{es}}$ remained stable after the first 5 minutes of the heat trial $\left(\Delta \mathrm{T}_{\mathrm{es}}=\right.$ $\left.0.12^{\circ} \pm 0.07^{\circ} \mathrm{C} / 10 \mathrm{~min}\right)$. Traditional cooling followed a linear decline $\left(\Delta \mathrm{T}_{\mathrm{es}}=0.17^{\circ} \pm 0.04^{\circ} \mathrm{C} / 10 \mathrm{~min}\right.$; $P<.001)$. Glabrous cooling enhanced the treatment effect by a steeper decline $\left(\Delta \mathrm{T}_{\mathrm{es}}=0.30^{\circ} \pm\right.$ $0.06^{\circ} \mathrm{C} / 10 \mathrm{~min} ; P<.001$ ), significantly different from traditional cooling by 2 -way analysis of variance $(P<.001)$.

Conclusions.-Application of CCP to glabrous skin surfaces was more effective for treating exercise-induced heat stress than the traditional CCP cooling intervention. This novel cooling technique may be beneficial as an adjunctive treatment for heat-related illness in the prehospital environment.

Key words: hyperthermia, heat-related illness, cooling, chemical cold packs, glabrous, exercise

\section{Introduction}

Heat-related illness is a common and preventable disease that if left untreated can culminate in potentially fatal heat stroke. Between 1999 and 2009, an average of 658 heat-related deaths occurred annually in the United States, a total of 7233 deaths with nearly all $(94 \%)$ occurring during May through September. ${ }^{1}$ Exertional heat stroke (EHS) is the second leading cause of death in young athletes. ${ }^{2}$ The mortality rate for EHS is

Presented as an oral presentation at the National EMS Providers Conference, Tucson, AZ, January 2014; and as a plenary presentation at the Wilderness Medical Society Annual Meeting, Breckenridge, CO, July 2013.

Corresponding author: Grant S. Lipman, MD, Division of Emergency Medicine, Always M121, Stanford, CA 94305 (e-mail: grantlip@hotmail. com). approximately $10 \%^{3}$ and, when combined with hypotension, increases to $33 \% .^{4}$ As heat-related morbidity and mortality is directly attributed to both the magnitude and duration of the hyperthermia, ${ }^{5,6}$ cooling needs to be initiated in the prehospital environment and continue throughout transportation to the emergency department.

There are both internal and external mechanisms for accumulating heat. Environmental factors such as thermal radiation, high temperatures, and humidity add to the body's intrinsic heat load and can reduce heat dissipation capacity. Similarly, when the body's metabolic heat production outpaces heat transfer, core temperature rises and heat illness can occur. Heat stroke may occur when internal core temperatures rise above a critical level, leading to a cascade of cellular and systemic responses. ${ }^{7-9}$ Cold-water immersion is the most 
effective means for treating heat stroke patients. ${ }^{10-14}$ However, in resource-limited settings (eg, ambulances, during natural disasters, or wilderness and military environments) adequate and effective cooling baths are usually not readily available. Because of their low cost, ease of use, and storage, chemical cold packs (CCP) placed on the neck, axillae, and groin have been recommended as a cooling method in prehospital ${ }^{15}$ and emergency medicine ${ }^{16}$ treatment algorithms. However, no studies have demonstrated this approach has an advantage over passive cooling. ${ }^{17,18}$

Glabrous (nonhairy) skin regions covering the soles of the feet, palms of the hands, and cheeks of the face may be preferable locations for CCP, as they contain densely packed subcutaneous vascular structures (retia venosa) under vasomotor and thermoregulatory control. The primary function of these subcutaneous retia venosa is to facilitate heat loss directly from the body core. ${ }^{19}$ By means of their capacity for high blood flow, ${ }^{20}$ these arteriovenous anastomoses have been shown to facilitate heat loss more than five times that of nonglabrous skin during exercise. ${ }^{21}$ The objective of this study was to compare the cooling rate of a novel application of CCP applied to glabrous skin surfaces vs CCP applied to the neck, axillae, and groin in subjects with exercise-induced hyperthermia during a 30 minute recovery period.

\section{Methods}

\section{SUBJECTS}

Ten healthy adult male volunteers participated in this prospective, nonblinded, randomized, crossover trial. Recruiting methods consisted of an announcement on local Stanford University and School of Medicine e-mail list servers as well as with a local search and rescue unit. All participants were physically active and passed a health screening survey administered by a study administrator. No individuals were screened and not enrolled in the study. The study was approved by the Stanford University School of Medicine institutional review board (clinicaltrials.gov identifier: NCT01694290).

\section{FACILITIES AND EQUIPMENT}

The trials were conducted in a $2.4 \times 3.3 \times 2.4 \mathrm{~m}$ (width, length, and height) temperature-controlled environmental chamber built to specifications. The trial conditions included an ambient temperature of $40^{\circ} \pm 0.5^{\circ} \mathrm{C}$, and relative humidity of $20 \%$ to $35 \%$. Treadmills (model SC7000; SciFit, Tulsa, OK) housed in the experimental chamber were used for the exercise portion of the trial. Baseline performance capacity tests were administered in a $23^{\circ} \mathrm{C}$ room.
Esophageal temperatures $\left(\mathrm{T}_{\mathrm{es}}\right)$ and heart rates were monitored throughout the trials. Heart rate monitors and data loggers (model S810; Polar Electro Oy, Kempele, Finland) were used to record and collect heart rate data at 5-second intervals. $\mathrm{T}_{\mathrm{es}}$ was measured with a commercially available general-purpose thermocouple probe (Mon-a-Therm No. 503-0028; Mallinckrodt Medical Inc, St. Louis, MO). These probes were self-inserted by the subjects through the nose to the base of the probe at a depth of 38 to $39 \mathrm{~cm}$ and held in place by a loop of surgical tape (Transpore, 3M Corporation, St. Paul, MN) adhered to the skin adjacent to the nares. The probes were connected to a desktop-based thermocouple transducer and data collection system (GEC Instruments, Gainesville, FL), which recorded temperature data at 1 -second intervals. At the end of each trial, temperature and heart rate data was downloaded to a central computer and transferred to a spreadsheet (Excel; Microsoft Corp, Redmond, WA) for subsequent analysis. Chemical cold packs (6" × 9", MediChoice product \#1480069904; Owens \& Minor, Richmond, VA) of the same brand and model used in the local emergency department were donated by the manufacturer.

\section{EXPERIMENTAL PROTOCOL}

Data were gathered between August 1, 2012, and November 23, 2012. The protocol required that each subject participate in 4 separate trials: a baseline physical performance assessment followed by three heat stress trials. Baseline assessments of physical performance, including maximal heart rates $\left(\mathrm{HR}_{\max }\right)$, were conducted in a $23^{\circ} \mathrm{C}$ room. This required participants to walk on a level treadmill at $5.63 \mathrm{~km} / \mathrm{h}$ for 3 minutes; the slope of the treadmill was then increased by $2 \%$ at 3 -minute intervals. Slope elevations increased until the participants could no longer proceed, thus yielding $\mathrm{HR}_{\max }$. The slope of the treadmill in the subsequent heat stress trials was set at $60 \%$ to $65 \%$ of the slope attained at the $90 \%$ $\mathrm{HR}_{\max }$, as based on methods designed by Grahn et $\mathrm{al}^{19,22,23}$ in previous studies.

Before each heat stress trial, nude weight was measured and each participant was equipped with a heart rate monitor and $\mathrm{T}_{\mathrm{es}}$ probe. The subjects performed all the trials clad in workout gear (lightweight shorts, shirts, and socks) and insulating outerwear: MOPP (Mission Oriented Protective Posture) military garments that are water impermeable and highly insulating (approximately 1.7 clo [R, -1.7]). Heat stress was induced by having the participants walk at $5.6 \mathrm{~km} / \mathrm{h}(3.5 \mathrm{miles} / \mathrm{h})$ uphill on a treadmill. The slope of the treadmill was adjusted for individual subjects so that heat stress (defined as $\mathrm{T}_{\mathrm{es}} \geq$ $39.2^{\circ} \mathrm{C}$ ) would be achieved in 30 to 40 minutes. The stop 
criteria for exercise were $\mathrm{T}_{\mathrm{es}}=39.2^{\circ} \mathrm{C}$, a heart rate of $95 \% \mathrm{HR}_{\max }$, or subjective fatigue. No subjects stopped on the basis of heart rate or fatigue criteria. Immediately after the termination of exercise, the subjects donned additional insulation (a polypropylene balaclava [Tullahoma Industries, Tullahoma, TN]; cold-weather mittens [Mountain Hardwear, Richmond, CA]; and commercially available disposable waterproof boot covers) and sat on a webbed chair in the hot room for a minimum of 30 minutes. After the 30-minute minimum rest and recovery period, the heart rate monitor and thermocouple probes were removed from the subject, and post-trial nude weight was measured.

The experimental manipulations were performed during the rest and recovery phase. The participants were subjected to three trials, each with a minimum of 24 hours between trials to allow for full recovery: 1) no treatment (control); 2) traditional treatment (one CCP applied to bilateral neck, axillae, and groin; six in total); or 3) glabrous treatment (one $\mathrm{CCP}$ applied to bilateral cheeks under the balaclava, palms [inside the gloves], and soles of the feet [inside of insulating boot covers]; six in total). The treatment order was no treatment followed by the two CCP treatments with the order randomized by coin flip. The CCP were agitated, applied, and then replaced every 9 minutes, corresponding to their average cold lifespan. ${ }^{24}$ No water was consumed during the trials, but after each trial each participant consumed the volume of water equivalent to the weight lost during the trial.

\section{STATISTICAL ANALYSIS}

The $T_{\text {es }}$ data were initially sampled at 1-second intervals and the heart rate data at 5-second intervals. $\mathrm{T}_{\mathrm{es}}$ and heart rate vs time graphs of the raw data were generated for each trial. The $T_{\text {es }}$ vs time plots were screened for swallowing artifact using computer software, and artifacts were removed from the data set. The data sets were reduced by sampling the data at 30 -second intervals. Cleaned data from the resting and recovery portion of the trials were selected and plotted as a function of time. The data analyzer was not blinded to the intervention arm.

Individual trial recovery $\mathrm{T}_{\mathrm{es}}$ data were grouped according to treatment, and further reduced by sampling the data at 5-minute intervals, and group mean and standard deviations were calculated at each 5-minute time point. The treatment group mean data were plotted against time. The rates of temperature changes $\left(T_{e s} v s\right.$ time) were calculated for the last 25 minutes of each trial (minutes 5 through 30 of the recovery period) using linear regression analysis (Microsoft Excel). The results of the linear regression analyses were sorted by subject and treatment and analyzed by two factor analysis of variance without replication and post hoc Student's $t$ tests.

\section{POWER ANALYSIS}

Sample size was calculated according to data from previous studies with similar protocols. ${ }^{19,22}$ To achieve $80 \%$ power ( $\alpha=.05,2$-tailed test), assuming intervention of the experimental method was a standard deviation greater than the traditional method, the minimal sample size to detect a statistically significant difference was 6 .

\section{Results}

Individual subject characteristics are listed in the Table. Exercise in the hot environment by participants clad in insulating clothing resulted in the anticipated rise in core temperature (Figure 1). The mean $\mathrm{T}_{\mathrm{es}}$ at the end of exercise for all trials was $39.2^{\circ} \pm 0.1^{\circ} \mathrm{C}$ (mean $\pm \mathrm{SD}$ ). No treatment produced little effect; mean $\mathrm{T}_{\mathrm{es}}$ decreased $0.3^{\circ} \pm 0.2^{\circ} \mathrm{C}$ in the first 5 minutes of rest and then

Table. Participant characteristics

\begin{tabular}{lcccc}
\hline Age $(y)$ & Treadmill incline $(\%)$ & $H R_{\text {max }}($ beats $/$ min $)$ & Height $(\mathrm{cm})$ & BMI $\left(\mathrm{kg} / \mathrm{m}^{2}\right)$ \\
\hline 19 & 17 & 203 & 193 & 20.4 \\
24 & 10 & 193 & 183 & 21.8 \\
26 & 11 & 187 & 175 & 23.7 \\
28 & 13 & 194 & 183 & 21.9 \\
29 & 15 & 201 & 178 & 23.7 \\
30 & 10 & 194 & 191 & 173 \\
30 & 9 & 192 & 183 & 26.2 \\
33 & 15 & 198 & 180 & 22.4 \\
42 & 10 & 173 & 175 & 24.2 \\
45 & 10 & & 180.7 \\
\hline
\end{tabular}

BMI, body mass index; $\mathrm{HR}_{\max }$, maximal heart rate. 


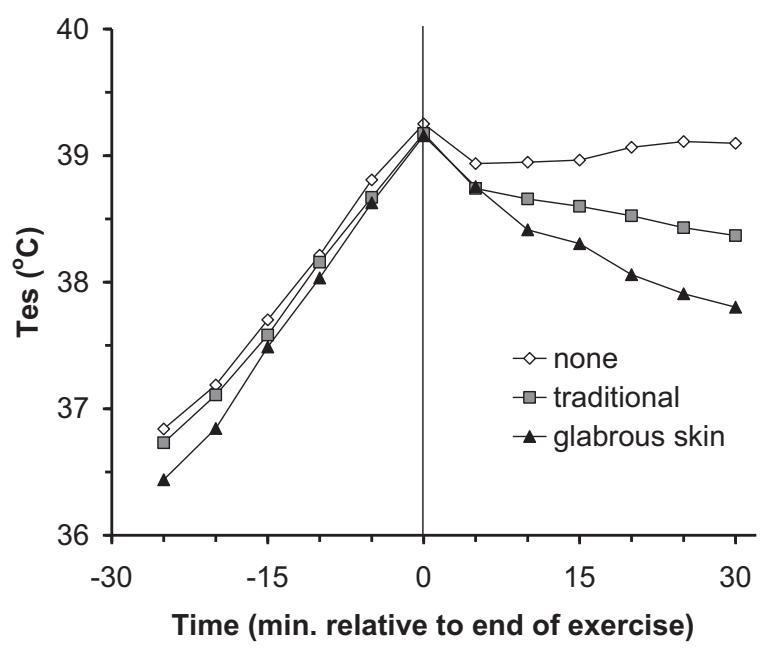

Figure 1. Individual data for exercise and recovery temperature characteristics for three trials, showing esophageal temperature $\left(T_{e s}\right)$ vs time of a heavily insulated subject during exercise and recovery in a hot environment. Treatments consisted of a control with no treatment (none), chemical cold packs (CCP) application to the neck, axillae, and groin (traditional), and CCP application to the glabrous skin regions of the hands, feet, and cheeks (glabrous skin).

remained stable throughout the remainder of the trial $\left(\Delta \mathrm{T}_{\mathrm{es}}=0.12^{\circ} \pm 0.07^{\circ} \mathrm{C} / 10 \mathrm{~min} ; R^{2}=0.007\right)$. Traditional cooling decreased mean $\mathrm{T}_{\mathrm{es}} 0.4^{\circ} \pm 0.2^{\circ} \mathrm{C}$ in the first 5 minutes of rest, followed by a linear decline in $\mathrm{T}_{\mathrm{es}}$ throughout the remainder of the rest period $\left(\Delta \mathrm{T}_{\mathrm{es}}\right.$ $\left.=0.17^{\circ} \pm 0.04^{\circ} \mathrm{C} / 10 \mathrm{~min} ; R^{2}=0.989 ; P<.001\right)$. Application of CCP to the glabrous skin regions further enhanced the treatment effect with a mean $\mathrm{T}_{\text {es }}$ decrease of $0.6^{\circ} \pm 0.2^{\circ} \mathrm{C}$ in the first 5 minutes of rest, followed by a steeper linear decline in core temperature throughout the remainder of the rest period $\left(\Delta T \mathrm{es}=0.30^{\circ} \pm\right.$ $0.06^{\circ} \mathrm{C} / 10 \mathrm{~min} ; R^{2}=0.983 ; P<.001 ;$ Figure 2). Figure 3 shows two-way analysis of variance with repeated measures that revealed statistically significant effects of glabrous placement of CCP vs traditional treatment at 5 to 30 minutes of the recovery period $(P<.001)$.

\section{Discussion}

This study demonstrated that the application of CCP to the glabrous skin regions is more effective for reversing heat stress than the traditional paradigm of cooling the neck, axillae and groin areas. Furthermore, this was the first study to quantify the effect of CCP applied to the glabrous skin areas of the cheeks, palms, and soles. This novel application of CCP to a heat-stressed patient is likely a safe and effective prehospital adjunctive cooling intervention when cold-water immersion and other known conductive and evaporative cooling treatments

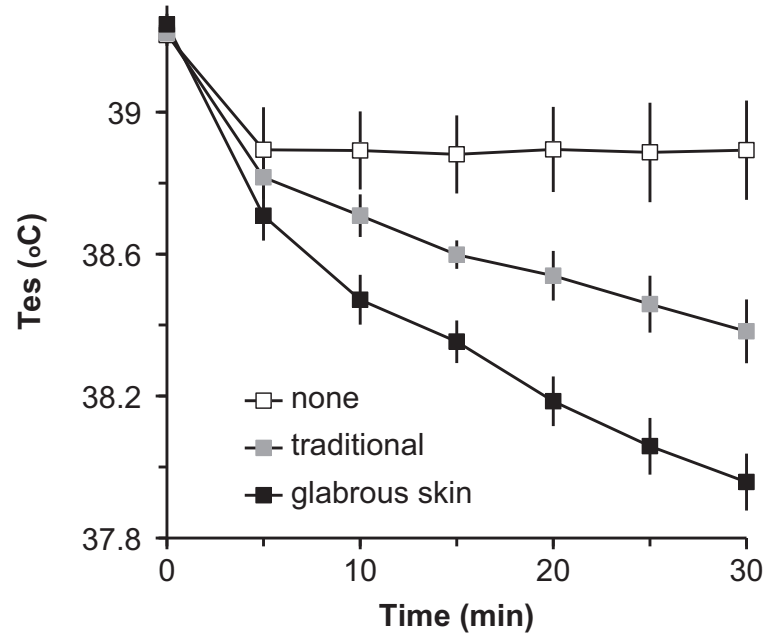

Figure 2. Group data for postexercise cooling characteristics, showing esophageal temperature $\left(\mathrm{T}_{\mathrm{es}}\right)$ vs time during recovery after exercise in thermally stressful conditions (group data, mean $\pm 95 \% \mathrm{CI}, \mathrm{n}=10$ ). Treatments consisted of a control with no treatment (none), chemical cold packs (CCP) application to the neck, axillae, and groin (traditional), and CCP application to the glabrous skin regions of the hands, feet, and cheeks (glabrous skin).

are not available. Cooling needs to be initiated during emergent transfer to definitive medical care, and application of CCP to glabrous skin surfaces of heat-stressed individuals is likely to be more beneficial than traditional CCP placement locations.

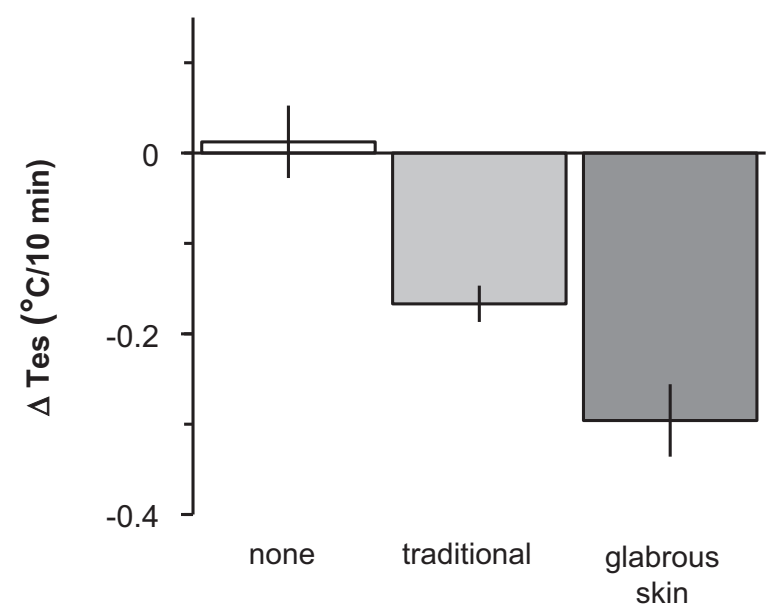

Treatment

Figure 3. Linear regression analysis of postexercise recovery rates, showing esophageal temperature $\left(\mathrm{T}_{\mathrm{es}}\right)$ vs time during postexercise recovery (group data, mean $\pm 95 \% \mathrm{CI}$ ). Treatments consisted of a control with no treatment (none), chemical cold packs (CCP) application to the neck, axillae, and groin (traditional), and CCP application to the glabrous skin regions of the hands, feet, and cheeks (glabrous skin). 
To effectively cool the hyperthermic patient in the prehospital setting, heat must be removed from the body via the skin surface. One of the primary surface sites for the delivery and dissipation of internal heat are the glabrous skin regions. During thermal stress, cardiac output increases by 6 to $7 \mathrm{~L} / \mathrm{min}$, splanchnic and renal perfusion decrease by $30 \%$, and mean arterial pressure decreases, while blood flow through the forearm (measured by plethysmography) increases six-fold. ${ }^{25}$ It is unlikely that cutaneous dilation of the microvascular capillary beds are accommodating the increased perfusion, as the six-fold increase in flow would require an increase in mean arterial pressure (rather than the observed decrease). ${ }^{22}$ Prior studies by Grahn et $\mathrm{al}^{19,21-23}$ have demonstrated that the unique subcutaneous microvascular structures that underlie the glabrous skin regions are a low-resistance pathway capable of accommodating the high volume of blood flow associated with heat stress with intrinsic heat transfer capabilities. As demonstrated in hand and forearm water-cooling studies, ${ }^{26-29}$ the intrinsic heat transfer capabilities reasonably explain why cooling was superior in the glabrous skin areas compared with the skin surface adjacent to large blood vessels.

One potential limiting factor in treating hyperthermia via surface cooling is the reflex vasoconstriction that could mitigate heat transfer. To avoid this, the temperature of the skin must remain above the temperature threshold for local vasoconstriction. The CCP of this study uses an endothermic reaction to reduce temperature and cool to approximately $13{ }^{\circ} \mathrm{C},{ }^{24}$ a temperature that is not associated with vasoconstriction, especially in the glabrous skin regions. Colder temperatures (as induced by ice packs) increase the likelihood of experiencing a vasomotor response and subsequently decreasing their local cooling effects. Although caution should be maintained in applying the studied cooling technique to older "classic" heat stroke victims whose comorbidities may inhibit peripheral vasculature responsiveness, application of CCP is unlikely to induce harm.

Each participant had at least 24 hours between trials. Given that heat acclimatization typically takes 10 to 14 days to occur, it is unlikely that the participants were acclimatized during their trials, and repeating the trials should not have affected the results. ${ }^{30}$

\section{LIMITATIONS}

This study was conducted in a controlled manner to isolate the enthalpy of the applied cooling techniques, where real-world treatment of heat-induced illness has removal of insulating layers as an initial intervention. ${ }^{14}$ Although the standard of care for thermally stressed individuals is to remove outer garments that reduce heat transfer across the general body surface to optimize passive cooling, our translational research model allowed us to both isolate and define the efficacy of the cooling treatments, which would have been limited without the insulation. Another limitation was that exercise-induced hyperthermia was generated in a laboratory setting, potentially limiting the generalizability to individuals experiencing environmental heat stroke. Randomized controlled trials with induced exertional heat stroke are ethically impossible to justify, and exercise-induced hyperthermia (with temperature $>38.5^{\circ} \mathrm{C}\left[101.3^{\circ} \mathrm{F}\right]$ ) is an accepted research model to test the efficacy of cooling interventions. $^{31}$

The study examined young, healthy male volunteers, whereas a majority of heat-related deaths are associated with the elderly. Geriatric individuals may have limited thermoregulatory capacity as a result of decreased cardiovascular, respiratory, and renal function associated with aging. Additionally, anticholinergic and diuretic medications often used by this demographic reduce vasodilation, sweating, and other heat-compensating mechanisms. ${ }^{32}$ Decreased vasodilation in the elderly may reduce the overall heat exchange through the glabrous surfaces, although it is unlikely that such reduction would result in cooling rates inferior to traditional methods. Female participants were not recruited for this study. It has been determined that sweat responses for thermoregulation differ between the sexes $^{33}$ and that cutaneous vasodilation is the dominant factor in thermoregulatory response in females. ${ }^{34}$ Although less cooling from sweating at the forehead, chest, back, and forearm has been seen than that of men, cutaneous blood flow was significantly greater on the thigh for women. These findings suggest that women may benefit more from glabrous cooling and that other body locales may also be used for enhanced cooling.

Only one study participant had a body mass index out of the normal range $\left(18.5-24.9 \mathrm{~kg} / \mathrm{m}^{2}\right)$ at $26.2 \mathrm{~kg} / \mathrm{m}^{2}$. Because of this limited range of body mass index, the experimental cooling technique may not be applicable to larger individuals. Further study is needed to include this cohort.

On average, 24 CCP were used on each study participant during the cooling process. This is a relatively large number of $\mathrm{CCP}$ that may be best suited for an EMS, as it may be a logistical limitation for individuals or small groups of first responders in the prehospital setting. Further studies are necessary to test the longevity of CCP to reduce the number used in addition to identifying CCP with longer thermal life spans. Given the study methodology, the research personnel and study participants were not blinded to the study objectives, which may have introduced bias. 


\section{Conclusions}

Application of CCP to glabrous skin surfaces was more effective for treating exercise-induced hyperthermia than the traditional paradigm of applying cold packs to the neck, groin, and axillae. This novel cooling technique may be a beneficial treatment adjunct to treating heatrelated illness in prehospital and resource-limited environments.

\section{Acknowledgments}

Thank you to MediChoice (Owens \& Minor) for donating the chemical cold packs, and to the volunteers, whose participation made this study possible.

\section{References}

1. Miniño AM, Murphy SL, Xu J, Kochanek KD. Deaths: final data for 2008. Natl Vital Stat Rep. 2011;59:1-126.

2. Centers for Disease Control and Prevention (CDC). Heat illness among high school athletes-United States, 20052009. MMWR Morb Mortal Wkly Rep. 2010;59:10091013.

3. Centers for Disease Control and Prevention (CDC). Heatrelated illnesses and deaths-United States, 1994-1995. MMWR Morb Mortal Wkly Rep. 1995;44:465-468.

4. Austin MG, Berry JW. Observations on one hundred cases of heatstroke. J Am Med Assoc. 1956;161:1525-1529.

5. Overgaard J, Suit HD. Time-temperature relationship in hyperthermic treatment of malignant and normal tissue in vivo. Cancer Res. 1979;39:3248-3253.

6. Adolph EF. Tolerance to heat and dehydration in several species of mammals. Am J Physiol. 1947;151:564-575.

7. Armstrong LE, Casa DJ, Millard-Stafford M, Moran DS, Pyne SW, Roberts WO. American College of Sports Medicine. American College of Sports Medicine position stand. Exertional heat illness during training and competition. Med Sci Sports Exerc. 2007;39:556-572.

8. Leon LR, Helwig BG. Heat stroke: role of the systemic inflammatory response. J Appl Physiol. 2010;109:19801988.

9. Bouchama A, Knochel JP. Heat stroke. N Engl J Med. 2002;346:1978-1988.

10. Armstrong LE, Crago AE, Adams R, Roberts WO, Maresh CM. Whole-body cooling of hyperthermic runners: comparison of two field therapies. Am J Emerg Med. 1996; $14: 355-358$.

11. Hadad E, Rav-Acha M, Heled Y, Epstein Y, Moran DS. Heat stroke: a review of cooling methods. Sports Med. 2004;34:501-511.

12. Smith JE. Cooling methods used in the treatment of exertional heat illness. Br J Sports Med. 2005;39:503-507.

13. Casa DJ, McDermott BP, Lee EC, Yeargin SW, Armstrong LE, Maresh CM. Cold water immersion: the gold standard for exertional heatstroke treatment. Exerc Sport Sci Rev. 2007;35:141-149.
14. Lipman GS, Eifling KP, Ellis MA, Gaudio FG, Otten EM, Grissom CK. Wilderness medical society practice guidelines for the prevention and treatment of heatrelated illness. Wilderness Environ Med. 2013;24: 351-361.

15. Millin MG. Chp 18. Heat/Cold Exposure. In: Krohmer JR, National Association of Emergency Medical Services Physicians eds. Clinical Aspects of Prehospital Medicine, Kendall Hunt Professional; 2009:173-179.

16. Platt M, Vicario S. Chp 141. Heat Illness. In: Marx J, Hockberger R, Walls R, eds. Rosen's Emergency Medicine: Concepts and Clinical Practice. Vol 1. 7th ed. Philadelphia, PA: Mosby; 2009:1896-1905.

17. Kielblock AJ, Van Rensburg JP, Franz RM. Body cooling as a method for reducing hyperthermia. An evaluation of techniques. S Afr Med J. 1986;69:378-380.

18. Richards D, Richards R, Schofield PJ, Ross V, Sutton JR. Management of heat exhaustion in Sydney's the Sun Cityto-Surf run runners. Med J Aust. 1979;2:457-461.

19. Grahn DA, Cao VH, Heller HC. Heat extraction through the palm of one hand improves aerobic exercise endurance in a hot environment. $J$ Appl Physiol. 2005;99:972-978.

20. Bergersen TK, Eriksen M, Walløe L. Effect of local warming on hand and finger artery blood velocities. Am J Physiol. 1995;269(2 Pt 2):R325-R330.

21. Heller HC, Grahn DA. Enhancing thermal exchange in humans and practical applications. Disruptive Sci Technol. 2012;1:11-19.

22. Grahn DA, Dillon JL, Heller HC. Heat loss through the glabrous skin surfaces of heavily insulated, heat-stressed individuals. J Biomech Eng. 2009;131:071005.

23. Grahn D, Brock-Utne JG, Watenpaugh DE, Heller HC. Recovery from mild hypothermia can be accelerated by mechanically distending blood vessels in the hand. $J$ Appl Physiol. 1998;85:1643-1648.

24. Phan S, Lissoway J, Lipman GS. Chemical cold packs may provide insufficient enthalpy change for treatment of hyperthermia. Wilderness Environ Med. 2013;24: $37-41$.

25. Rowell LB. Cardiovascular aspects of human thermoregulation. Circ Res. 1983;52:367-379.

26. House JR, Holmes C, Allsopp AJ. Prevention of heat strain by immersing the hands and forearms in water. $J R$ Nav Med Serv. 1997;83:26-30.

27. Kuennen MR, Gillum TL, Amorim FT, Kwon YS, Schneider SM. Palm cooling to reduce heat strain in subjects during simulated armoured vehicle transport. Eur J Appl Physiol. 2010;108:1217-1223.

28. Selkirk GA, McLellan TM, Wong J. Active versus passive cooling during work in warm environments while wearing firefighting protective clothing. J Occup Environ Hyg. 2004; 1:521-531.

29. Giesbrecht GG, Jamieson C, Cahill F. Cooling hyperthermic firefighters by immersing forearms and hands in 10 degrees $\mathrm{C}$ and 20 degrees $\mathrm{C}$ water. Aviat Space Environ Med. 2007;78:561-567. 
30. Cheung SS, McLellan TM. Heat acclimation, aerobic fitness, and hydration effects on tolerance during uncompensable heat stress. J Appl Physiol. 1998;84:1731-1739.

31. McDermott BP, Casa DJ, Ganio MS, et al. Acute wholebody cooling for exercise-induced hyperthermia: a systematic review. J Athl Train. 2009;44:84-93.

32. Dinarello CA, Porat R. Fever and Hyperthermia. In: e Ed. Longo DL, Kasper DL, Jameson JL, Fauci AS, Hauser SL, Loscalzo J, ed. Harrison's Principles of Internal Medicine. 18th ed. New York, NY: McGraw Hill Medical; 2012: 143-147.

33. Kaciuba-Uscilko H, Grucza R. Gender differences in thermoregulation. Curr Opin Clin Nutr Metab Care. 2001;4:533-536.

34. Inoue Y, Tanaka Y, Omori K, Kuwahara T, Ogura Y, Ueda H. Sex- and menstrual cycle-related differences in sweating and cutaneous blood flow in response to passive heat exposure. Eur J Appl Physiol. 2005;94:323-332. 